\title{
CONF-84/157--64
}

To be published in the Proceedings of the Materials Research Society Symposium on "Energy Beam-Solid Interactions and Transient Thermal Processing" held in Boston, Massachusetts, November 26-30, 1984.

CONE $-841157--64$

DE85 005568

\section{DOPANT INCORPORATION IN SILICON DURING MONEQULIBRIUM SOLIDIFICATION: COMPARISON OF TWO PROCESSES}

E. P. Fogarassy, D. H. Lowndes, J. Narayan, and C. W. White

\section{DISCLAIMER}

This report was prepared as an account of work sponsored by an agency of the United States Government. Neither the United States Government nor any agency thereof, nor any of their employees, makes any warranty, express or implied, or assumes any legal liability or responsibility for the accuracy, completeness, or usefulness of any information, apparatus, product, or process disclosed, or represents that its use would not infringe privately owned rights. Reference herein to any specific commercial product, process, or service by trade name, trademark, manufactsrer, or otherwise does not necessarily constitute or imply its endorsement, recommendation, of favoring by the United States Government or any agency thereof. The views and opinions of authors expressed herein do not necessarily state or reflect those of the United States Government or any agency thereof.

SOLID STATE DIVISION

OAK RIDGE NATIONAL LABORATORY

Operated by

MARTIN MARIETTA ENERGY SYSTEMS, INC. under

Contract No. DE-AC05-840R21400

for the

U.S. DEPARTMENT OF ENERGY

OAK RIDGE, TENNESSEE 37831

January 1985 
E. P. Fogarassy, ${ }^{+}$D. H. Lowndes, ${ }^{\star \star}$ J. Marayan, ${ }^{++}$and C. W. White

+Guest scientist from the Centre National de la Recherche Scientifique, Strasbourg, 67037, FRANCE

* Sol id State Division, Oak Ridge National Laboratory, Oak Ridge. TN 37831. ${ }^{+}$On sabbatical at the Microelectronics Center of North Carolina, Research

Triangle Park, NC 27709 and the Materials Engineering Department, North Carolina State University, Raleigh, NC 27650.

\section{ABSTRACT}

The incorporation properties of implanted or deposited $\mathrm{Sb}$ into the silicon lattice during laser irradiation with a UW laser has been studied. For both implanted or deposited $\mathrm{Sb}$, we find a maximum substitutional concentration of $2.1 \times 10^{21} / \mathrm{cm}^{3}$. following laser melting and solidification at $V \approx 6 \mathrm{~m} / \mathrm{sec}$. In both cases, substitutional solubility is limited by interfacial instabilities which develop during regrowth. For the deposited case we observe in addition a much larger cellular microstructure which may result from convection induced instabilities.

\section{INTRODUCTION}

The rapid deposition of energy from a pulsed laser into the near surface of silicon leads to melting of crystal, followed by liquid phase epitaxial regrowth from the underlying substrate. During regrowth, velocities of several meters per second can be achieved [1]. Implanted or deposited elements from group III and group V can be incorporated into substitutional sites in the silicon lattice with concentrations far in excess of their equilibrium solubility limit during the rapid solidification process [2,5]. In this study, we have compared the incorporation of implanted or deposited $S b$ into the Si lattice as a result of irradiation with a pulsed KrF ultraviolet laser. Measurements have been made of the surface melt duration and the total and substitutional distribution profiles of the dopant. In both cases, mechanisms limiting dopant incorporation at high concentration have been determined. Finally we discuss the formation of a new type of cellular structure in surface of deposited samples.

\section{EXPERIMENTAL CONDITIONS}

The samples used in this study were single crystal silicon of $\langle 100\rangle$ orientation. A part of these crystals were implanted at room temperature with antimony ions of $150 \mathrm{keV}$ energy. The implantation doses ranged from $2 \times 10^{16}$ to $5 \times 10^{16} \mathrm{~cm}^{-2}$. Thin films of antimony (50-100 A) were deposited on similar substrate surfaces by electron gun evaporation in vacuum $\left(P \sim 10^{-6}\right.$ Torr $)$. These samples were irradiated with $\mathrm{KrF}$ excimer laser pulses $(\lambda=248 \mathrm{~nm})$ of $35 \mathrm{~ns}$ FWh. The laser energy density could be waried between 0.5 and $1.3 \mathrm{~J} / \mathrm{cm}^{2}$. The total and substitutional dopant distribution profiles were determined by Rutherford backscattering and ionchanneling measurements performed along the $\langle 110\rangle$ direction. A $2.5 \mathrm{MeV}$ ${ }^{4} \mathrm{He}{ }^{+}$ion beam (diameter $=1 \mathrm{~mm}$ ) was used, and the energy of the backscattered particles was measured by a cooled detector. This permitted a depth resolution of about 150 \& to be achieved. 
Time-resolved optical reflectivity measurements to oatermine the onset and duration of surface melting were performed using a $\approx$ linke probe laser beam $(\lambda=633 \mathrm{~nm})$ incident at $10^{\circ}$ to the surface normal and focussed to a 35 un $\left(e^{-1}\right)$ spot diameter. Reflected light was detected using a silicon avalanche photodiode and a storage oscilloscope. Transmission electron microscopy (TEM) results were obtained using a Phillips (EM-400) analytical microscope.

\section{RESULTS \\ RBS Experiments}

Figure 1 shows the measured total and substitutional concentration !profiles of implanted Sb (150 keV, $5 \times 10^{16} \mathrm{~cm}^{-2}$ ) after laser annealing at energy density $E=1 \mathrm{~J} / \mathrm{cm}^{2}$. The as-implanted profile is approximately Gaussian with a peak at $750 \mathrm{~A}$. Laser annealing causes a broadening of the Sb distribution, both toward the surface and deeper in depth, which is characteristic of a diffusion in liquid Si. The melt depth, $2000 \mathrm{~A}$, has been deduced from channeling spectra. The substitutional concentration of antimony reaches to a value of $2.1 \times 10^{21} \mathrm{~cm}^{-3}$, and then becomes constant or decreases slightly in the near surface region. This concentration, equal to that found by using pulsed ruby laser, exceeds the retrograde maximum solutiblity limit at thermal equilibrium by a factor of about 30 (6 $\times 10^{19} \mathrm{~cm}^{-3}$ at $T=1200^{\circ} \mathrm{C}$ ) [6]. The value of $2.1 \times 10^{21} / \mathrm{cm}^{3}$ is the solubility limit of $\mathrm{Sb}$ in $\mathrm{Si}$ for interface velocities (deduced from heat flow calculations) close to $6 \mathrm{~m} / \mathrm{s}$. Figure 2 shows results obtained after irradiating an Sb film $(-80$ A) deposited on Si. Following laser irradiation (E $\left.=1 \mathrm{~J} / \mathrm{cm}^{2}\right)$, the dopant distribution is composed of two distinct regions, an in-depth profile and a rich antimony surface peak. The in-depth profile results from diffusion of Sb into liquid silicon during liquid phase epitaxial regrowth. The Sb substitutional distribution profile increases continuously to the surface, reaching a maximum concentration of $2.1 \times 10^{21}$ $\mathrm{cm}^{-3}$, a value which is somewhat higher than values found after pulsed ruby laser irradiation of deposited Sb layers $\left(\sim 1.1 \times 10^{21} \mathrm{~cm}^{-3}\right)$. There is no loss of Sb by evaporation during laser irradiation. We find $-34 \%$ of the initial $\mathrm{Sb}$ in the surface peak and $-66 \%$ in the in-depth profile following the laser treatment. The proportion of incorporated Sb can be increased by repeating the laser irradiations, as shown in Figs, 3 and 4 for 10 and 20 shots respectively $\left(E=1 \mathrm{~J} / \mathrm{cm}^{2}\right)$. During repeated shots, the Sb surface peak acts as a diffusion source. For 20 shots, we measure an incorporation of $\sim 83 \%$, with only $17 \%$ of the initial deposited antimony remaining in the

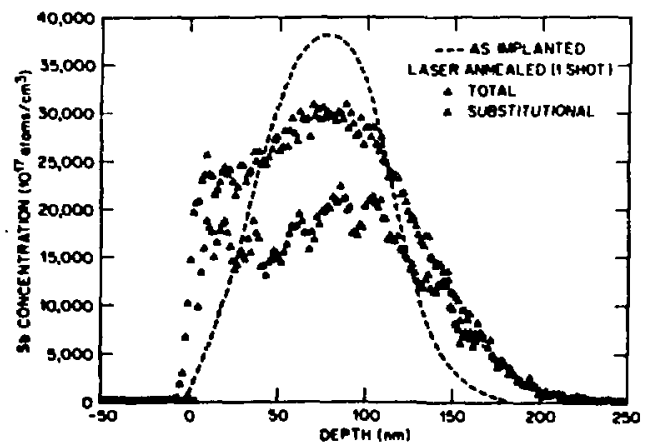

Fig. 1. Total and Substitution:? Concentrations for $122 \mathrm{Sb}(150 \mathrm{keV}$. $4 \times 10^{16} \mathrm{~cm}^{-2}$ ) in $\langle 100\rangle \mathrm{Si}$ after Excimer Laser Annealing (1 Shot) residual surface peak. In Fig. 4, the depth of the plateau in the Sb distribution profile provides an appropriate measure of the depth of melting $(-2500$ A) during the laser induced diffusion process. This value is considerably larger than the depth predicted by calculations for crystalline Si ( 1000 A). The in-depth St concentration in Fig. 4 is fully substitutional since the maximum concentration is less than the solubility limit of $2.1 \times$ $10^{21} / \mathrm{cm}^{3}$ due to repeated melting and diffusion in the liquid. 


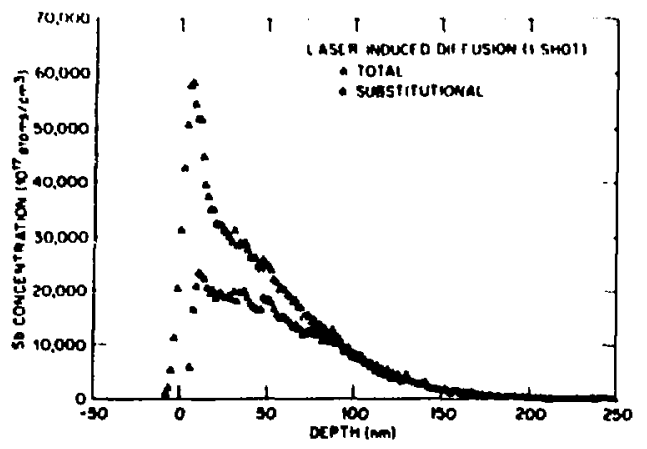

Fig. 2. Total and Substitutional Concentrations for a Thin Film of Sb (80A) Deposited on $\langle 100\rangle$ Si After Excimer Laser Induced Diffusion

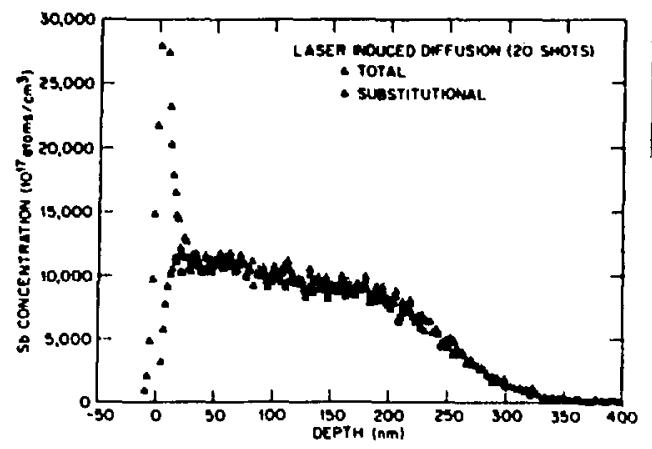

Fig. 4. Total and Substitutional Concentrations for a Thin Film of Sb (80A) Deposited on $\langle 100\rangle$ Si After Excimer Laser Induced Diffusion

\section{Reflectivity Measurements}

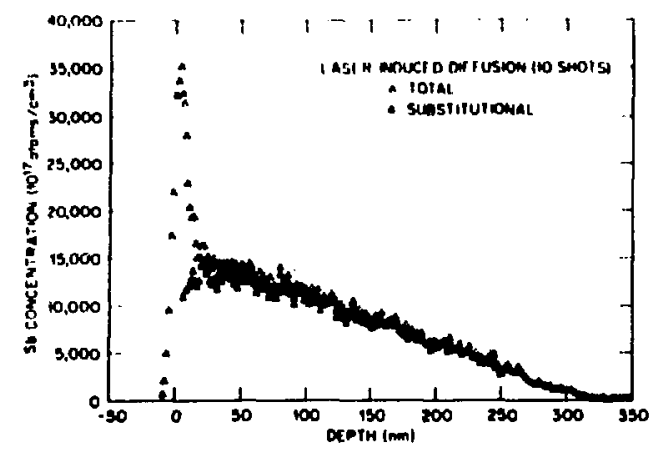

Fig. 3. Total and Substitutional Concentrations for a Thin Film of SD $(80 A)$ Deposited on $\langle 100\rangle$ Si After Excimer Laser Induced Diffusion

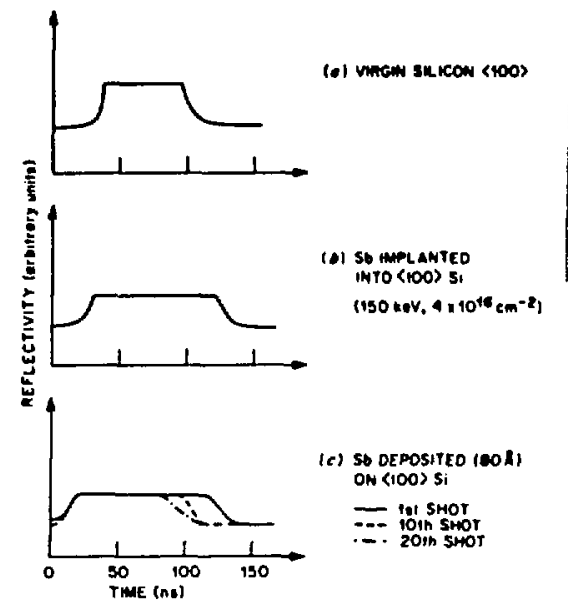

Fig. 5. Surface Reflectivity During Melting by a 35 ns Pulsed KrF UV Laser ( $E=1 \mathrm{~J} / \mathrm{cm}^{2}$ )

Time-resolved optical reflectivity measurements were used to obtain better insight into the surface melt dynamics resulting from laser irradiation [7]. Time resolved reflectivity measurements were performed on (a) virgin silicon, (b) Sb implanted samples and (c) Sb deposited layers during the UV laser treatment $\left(E=1 \mathrm{~J} / \mathrm{cm}^{2}\right)$. The results are reported in Fig. 5 . In all cases, the sharp transition to the high reflectivity phase $(R \cong 72 \%$ at $\lambda=633 \mathrm{~mm}$ ) is characteristic of molten silicon. Surface melt durations measured on Sb implanted and deposited layers ( $\mathrm{t} \sim 95 \mathrm{~ns}$ ) are significantly larger than for virgin silicon $(t \sim 55 \mathrm{~ns})$. However, for the deposited case, we measure a decrease of surface melt duration when we repeat the laser treatment several times at the same energy density. Surface melt duration decreases from -95 ns on the first shot to -64 ns on the 20th shot, a value thich is only marginally greater than that measured on virgin Si. This behavior may be related to the decrease of the antimony contailied in the surface peak with increasing number of pulses, as observed by RBS experiments. This means that the deposition of Sb strongly modifies the melt dynamics of laser treated crystalline silicon. At the $\mathrm{KrF}$ wavelength $(\lambda=248 \mathrm{~mm})$, the absorption coefficient of crystalline silicon is very high $\left(\alpha \sim 10^{6} \mathrm{~cm}^{-1}\right)$, and it is reasonable to assume that this parameter is not significantly modified in presence of a thin antimony layer. In addition, we measure a decrease of the solid state reflectivity (from $\sim 65 \%$ to 38.6\%) on the as-deposited sample. This result is not well understood, but 
it may be related to interference effects in the thin layer. A decrease of reflectivity increases the amount of energy available to melt the sample. Another important parameter is the melting temperature of the surface layer. Since the melting point of antimany $\left(T_{M}=630^{\circ} \mathrm{C}\right)$ is lower than for silicon $\left(T_{M}=1410^{\circ} \mathrm{C}\right)$, the melting of the Sb deposited layer does not require as much energy as for crystalline silicon. This is suggested by the earlier time of the onset of melting measured on Sb deposited layers (Fig. 5C). This means that for identical irradiation conditions more energy is available to melt the underlying silicon when it is covered with a thin film of antimony through the formation of a Sb-Si eutectic alloy. The main consequence of this is to increase thickness of the melted silicon layer and the surface melt duration, in good agreenent with experimental results.

\section{Transmission Electron Microscopy}

Figure $6(a)$ is a plan-view micrograph showing the formation of cells in the ion implanted and laser annealed $\left(1.0 \mathrm{~J} / \mathrm{cm}^{2}, 1\right.$ shot) specimens. Cell formation starts at a depth $\sim 2300 \mathrm{~A}$, in agreement with ion channeling results of Fig. I which indicate differences between substitutional and total concentrations at this depth. The average cell size in Fig. 6a is $\sim 500 \mathrm{~A}$ and cell walls are perpendicular to the surface. Figure $6(\mathrm{~b})$ shows a selected-area-diffraction pattern in which the extra spots correspond to the pure antimony phase. The TEM results from deposited and laser annealed $\left(1.0 \mathrm{~J} / \mathrm{cm}^{2}\right)$ samples are displayed in Figs. 7 and 8 . Figure 7 shows the existence of two types of cells following the initial laser pulse: small cells with an average size of 350 \& are associated with the walls of large cells of average size $3000 \mathrm{~A}$. Figure 8 shows the formation of cells as a function of number of laser pulses in deposited samples. After one pulse, we observed small and large cells including denuded zones in the middle of large cells. The electron micrograph in Fig. 8 a was taken under kinematical diffraction conditions, where small cells near the wall are clearly delineated. The formation of cells starts at a depth of $850 \mathrm{~A}$, in agreement with ion channeling results of Fig. 2. After irradiation with 10

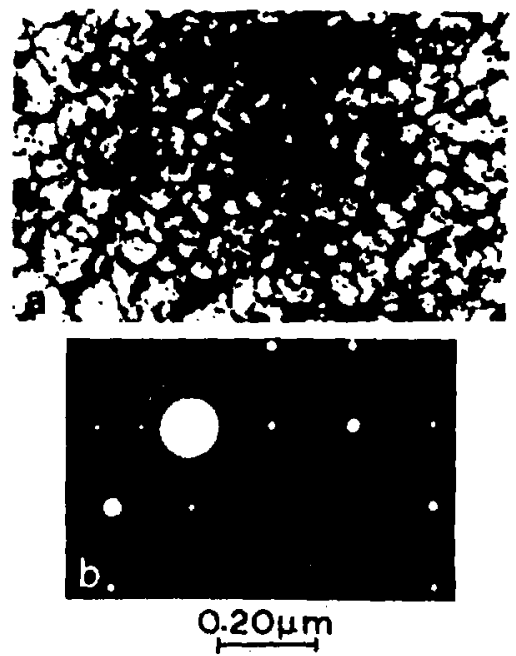

Fig. 6. Formation of cells in Sb implanted ( $150 \mathrm{KeV}, 5 \times 10^{16} \mathrm{~cm}^{2}$ ) and laser annealed silicon:

(a) plan view micrograph, (b) diffraction pattern showing $\mathrm{Sb}$ spots.

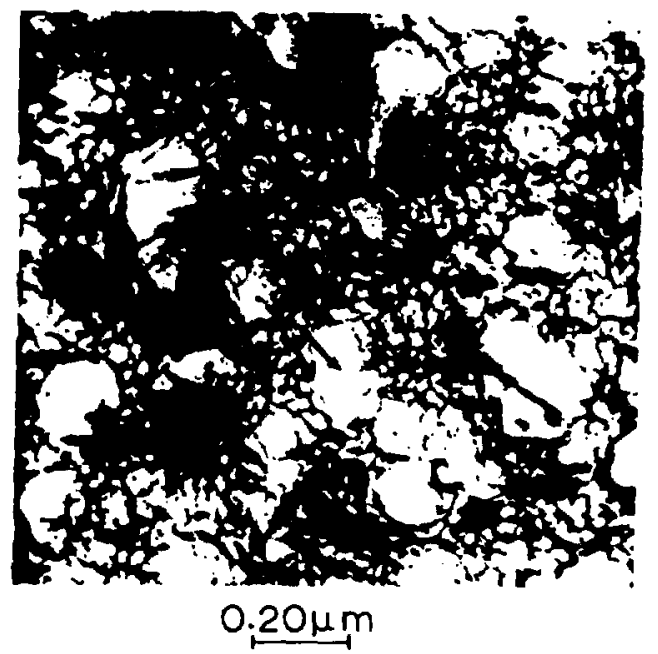

Fig. 7. Formation of two types of cells in Sb deposited $(80$ A) and laser treated silicon. 


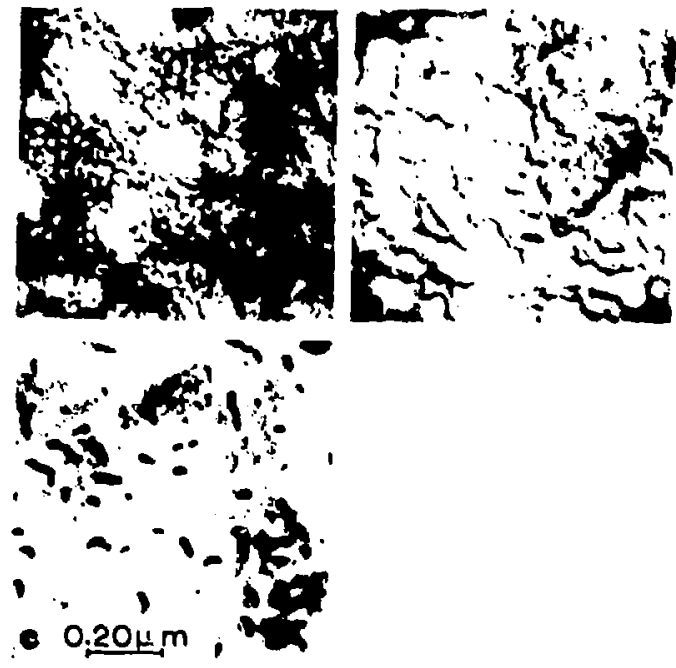

Fig. 8. Cells in Sb deposited layers as a function of number of laser shots ( $E=1 . \mathrm{J} / \mathrm{cm}^{2}$ )

(a) 1 shot, (b) 10 shots,

(c) 20 shots. pulses (Fig. Bb) the presence of cells was observed in the top 200 A only. The width of this region decreased to 150 a after irradiation with 20 pulses (Fig. $8 \mathrm{c}$ ). The residual structure in Figs. $8(b)$ and $(c)$ seems to be associated with large cells.

The formation of small cells both in surface of implanted and deposited layers is presumably the result of interfacial instability caused by constitutional supercooling during solidification $[8,9]$. During solidification of a dilute binary alloy, a planar liquid-solid interface can become morphologically unstable above a certain solute concentration at a given velocity of solidification. The sizes of small cells are in good agreement with calculations based upon the Mullins-Sekerka [10] theory modified to include the dependence of distribution coefficient upon the velocity of solidification. The concentration of Sb corresponding to the development of interface instability is

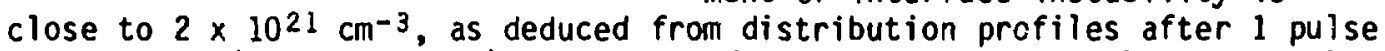
irradiation (Figs. 1 and 2). However, for the deposited samples the small size cellular structure disappears after 10 laser pulses (Fig. 8b) since the maximum substitutional Sb concentration does not exceed $1.5 \times 10^{21} \mathrm{~cm}^{-3}$ (Fig. 3 ), due to the redistribution in depth of the dopant during repeated melting and liquid phase diffusion. This value is less than that required for the development of interface instability. The formation of large cells seems to be related to the convection induced instability leading to segregation of solute near the large cell walls. The formation of small cells in certain middle regions of the large cells is suppressed (as shown by the arrow on Fig. 7) because the transport of the solute from the middle of the large cells reduces the concentraition to a value which is less than that required for the formation of cells by constitutional supercooling.

\section{DISCUSSION}

To better understand these results, we must consider the thermodynamic process which occur during the irradiation of silicon with a uv laser. The absorption coefficient for either crystalline or amorphous Si at $\lambda=248 \mathrm{~nm}$ is $\sim 10^{6} \mathrm{~cm}^{-1}$, which is much higher than that at the fundamental frequency of the rubj laser $(\lambda=694 \mathrm{~nm})$ where $\alpha=5 \times 10^{3} \mathrm{~cm}^{-1}$ in crystalline Si and $\alpha=5 \times 10^{4} \mathrm{~cm}^{-1}$ in amorphous Si. Thus, at the uv wavelength, the radiation is absorbed in the first few hundred angstroms generating very high temperature gradients both in crystalline and amorphous Si and consequently higher regrowth velocities, as deduced from calculations $\left(V_{c-S i}=\right.$ $\left.V_{a-S j}=6 \mathrm{~m} / \mathrm{sec}\right)[11]$. This is higher than calculated regrowth velocities resulting from ruby laser irradiation of similar pulse duration ( $V_{C-S i}=$ $3 \mathrm{~m} / \mathrm{sec} ., v_{a-S i} \simeq 4.5 \mathrm{~m} / \mathrm{sec}$.). Therefore, the substitutional solubility is similar for deposited or implanted Sb because the regrowth velocity is approximately the same. At the ruby wavelength, the solubilities are different presumably because the velocity of regrowth is different. The value 
of $2.1 \times 10^{21} / \mathrm{cm}^{3}$ is limited by interface instabilities which develop during regrowth and lead to the formation of a well defined small size cellular structure, which is observed in surface of both deposited and implanted samples. However, the experimental results have shown the presence of a second type of cell in the surface of the deposited layer. These large cells, with a size of $3000 \mathrm{~A}$, which is comparable to the liquid layer thickness might be attributed to convection induced instability forming "Bénard cells", as observed by van Gurp et al. [12], and by Possin et al. [13] on laser treated thin metallic films of cobalt and nickel deposited on silicon. ine thin liquid films are known to be dominated by surface tension forces. There is a mell known tendency for the liquid film to ball up and form droplets on the surface of the substrate. In case of a thin liquid film of $\mathrm{Sb}$ on liquid silicon, there is a large difference in surface tensions for these two materials $\left(\delta_{S f} \sim 750\right.$ dynes $/ \mathrm{cm}, \delta_{S b} \sim 350$ dynes $/ \mathrm{cm}$ ). This difference can lead to a large surface tension gradient over a small lateral distance. This results in the fluid film breaking up into small convective cells of size comparable to the depth of the melted layer.

\section{CONCLUSION}

We have demonstrated, in this study, that the substitutional incorporation of antimony in laser treated silicon does not depend on deposition or implantation, but is only a function of the velocity of liquid-solid interface during resolidification of the molten layer. In the two cases (implanted and deposited) the solubility limit of Sb is $2.1 \times 10^{21} \mathrm{~cm}^{-3}$, and is limited by interface instabilities which develop during regrowth at $V \simeq 6 \mathrm{~m} / \mathrm{sec}$ and lead to the formation of a small size cell structure in the near-surface region. However, in the Sb deposited and laser annealed samples, we observe a second type of cellular structure, an order of magnitude larger in size, (Benard cells). This larger structure is believed to be related to convective movements which take place in the surface of deposited samples during laser treatment.

\section{REFERENCES}

1. See for example, Laser Annealing of Semiconductors, ed. by J. M. Poate and James W. Mayer, Academic Press, New York (1982).

2. C. W. White, S. R. Wilson, B. R. Appleton, and F. W. Young, Jr., J. Appl. Phys. 51, 738 (1980).

3. C. W. White, J. de Physique T44, 145 (1983).

4. E. Fogarassy, R. Stuck, J. J. A. Grob, and P. Siffert, Laser and Electron Beam Processing of Material, ed. by C. W. White, and P. S. Peercy, Academic Press, New York (1980) p. 117.

5. E. Fogarassy, R. Stuck, M. Toulemonde, D. Salles, and P. Siffert, J. Appl. Phys. 54, 5059 (1983).

6. F. Trumbore, Bell Sj'st. Tech. J. 39, 205 (1960).

7. D. H. Auston, C. M. Surko, T. N. C. Venkatesan, R. E. Slusher, and J. A. Golovchenko, App 1. Phys. Lett. 33(5) 437 (1978).

8. J. Narayan. H. Naramoto, and C. W. White, J. Appl. Phys. 53, 912 (1983).

9. J. Narayan, J. Appl. Phys. 52, 1283 (1981).

10. W. W. Mullins and R. F. Sekerka, J. Appl. Phys. 35, 444 (1964).

11. M. Aziz, private communication.

12. G. J. van Gurp, G. E. J. Eggermont, Y. Tamminga, W. T. Stacy, and J. R. M. Gijsbers, Appl. Phys. Lett. 35, 273 (1979).

13. G. E. Possin, H. G. Parks, and S. W. Chiang, P. 73 in Ref. 7. 